\title{
Kinetics, Dynamics and Energy of Solid on the Example of a Tool Fixed Flexibly: Part 3 - Energy
}

\author{
Zdzisław Pluta, Tadeusz Hryniewicz* \\ Koszalin University of Technology, Raclawicka 15-17, 75-620 Koszalin, Poland \\ *E-mail address: Tadeusz.Hryniewicz@tu.koszalin.pl
}

\begin{abstract}
This work is a continuation of the problems of kinetics and dynamics of solid on the example of a tool fixed flexibly under cutting. Present work is concerned on the development of work and energy. A special attention has been paid to the work description by underlying a distinctness and lack of connection with the energy notion. Polarization of these two magnitudes has been revealed. An adequate and extended definition of energy in general, with mechanical energy in particular, is formulated. There are three kinds of mechanical energy considered, located on the stable static potential field being one of the limits of the machining space-time. They are the following energies: repel, inertial, and gravitational. Proper measures/potentials have been assigned to these energies, treating the energy as a mental notion, having no physical meaning in contrast to the potential as the physical magnitude.
\end{abstract}

Keywords: Tool; Machining space-time; Potential field; Work; Energy; Potential; Mechanics

\section{INTRODUCTION}

The Authors' work [1] is referred to, concerning an adequate approach to cutting by the tool fixed flexibly. Part 1 of the paper was focused on the kinetics [2], whereas in Part 2 the dynamics of the system was considered extensively [3].

Stored energy of the tool will be provided on the basis of energy notion, the properly understood mechanical energy of a solid/material body. An important task is to provide descriptions of the phenomena on adequately defined fundamental notions.

\section{TYPES OF WORKS IN THE MACHINING SPACE-TIME}

In the cutting/machining process, the actual types of work are as follows: plastic work, the works related to elastic strain energy, heat generation, tool-work/tool-chip friction, tool vibration, etc.

To simplify the calculations, for our consideration in the machining space-time, the following types of mechanical works are taken into account: workpiece work, work over tool, and work over tool fix with Earth (gravitational fix). 
The mechanical works are as follows: repel $L_{R}$, inertia $L_{B}$, and gravitation $L_{Q}$. The repel work, performed by the workpiece, is the sum of works performed over tool and tool fix with the Earth. Therefore

$$
L_{R}=L_{B}+L_{Q}
$$

All these works are performed in vertical direction, in accordance with the direction of particular forces, that are the following forces: repel $R_{z}$, inertia $B_{z}$, and gravity $Q$. The work is a product of force and path length (on the direction of this measure of determined reason), if the force is a constant magnitude.

This refers to the gravity force. If a force is characteristic with a determined variability, then the corresponding work should be expressed by means of integral. Therefore all the works are expressed by formulae

$$
\begin{gathered}
L_{B}=\int_{0}^{z^{*}} B_{z}(z) d z=m \int_{0}^{z^{*}} p_{z}(z) d z \\
L_{Q}=\int_{0}^{z^{*}} Q d z=Q \cdot z^{*}=m g \cdot z^{*} \\
L_{R}=\int_{0}^{z^{*}} R_{z}(z) d z=\int_{0}^{z^{*}} B_{z}(z) d z+\int_{0}^{z^{*}} Q d z=m \int_{0}^{z^{*}} p_{z}(z) d z+m g \cdot z^{*}
\end{gathered}
$$

where the upper limit of integration $z^{*}$ corresponds with the same with the height of the machining space-time (see Fig. 2 [2]).

Now the acceleration $p_{z}$ will be expressed as the function of path length $z$. To do this, the function expressed by formula (1.4 [2]), then $z=f(t)$, is to be transformed. Therefore

This is to separate the exponential term to present it as the function of coordinate $z$.

$$
e^{-\frac{t}{T_{o}}}=\frac{2 z^{*}-z}{2 z^{*}}=1-\frac{z}{2 z^{*}}
$$

It will be substituted to the formula (1.11 [2]), that results in

$$
p_{z}=\frac{2 z^{*}}{\left(T_{o}\right)^{2}}\left(1-\frac{z}{2 z^{*}}\right)=\frac{2 z^{*}}{\left(T_{o}\right)^{2}}-\frac{1}{\left(T_{o}\right)^{2}} z=\frac{1}{\left(T_{o}\right)^{2}}\left(2 z^{*}-z\right)
$$

Now, by expressing the inertia force $B_{z}$ by the product of mass $m$ and acceleration $p_{z}$, according to the formula (2.5 [3]), one obtains

$$
B_{z}=m \cdot p_{z}=m \frac{2 z^{*}}{\left(T_{o}\right)^{2}} e^{-\frac{t}{T_{o}}}=m \frac{2 z^{*}}{\left(T_{o}\right)^{2}}\left(1-\frac{z}{2 z^{*}}\right)=
$$


and

$$
=\frac{2 m \cdot z^{*}}{\left(T_{o}\right)^{2}}-\frac{m}{\left(T_{o}\right)^{2}} z=\frac{m}{\left(T_{o}\right)^{2}}\left(2 z^{*}-z\right)
$$

$$
\begin{aligned}
R_{z}= & B_{z}+Q=\frac{2 m \cdot z^{*}}{\left(T_{o}\right)^{2}}-\frac{m}{\left(T_{o}\right)^{2}}+m g= \\
= & \frac{2 m \cdot z^{*}}{\left(T_{o}\right)^{2}}+m g-\frac{m}{\left(T_{o}\right)^{2}} z
\end{aligned}
$$

By substituting the formula (3.7) in the place of integrand (3.2), one obtains

$$
\begin{gathered}
L_{B}=m \int_{0}^{z^{*}}\left[\frac{2 z^{*}}{\left(T_{o}\right)^{2}}-\frac{1}{\left(T_{o}\right)^{2}} z\right] d z=\frac{2 m \cdot z^{*}}{\left(T_{o}\right)^{2}} \int_{0}^{z^{*}} d z-\frac{m}{\left(T_{o}\right)^{2}} \int_{0}^{z^{*}} z d z= \\
=\frac{2 m \cdot z^{*}}{\left(T_{o}\right)^{2}}[z]_{0}^{z^{*}}-\frac{m}{\left(T_{o}\right)^{2}}\left[\frac{z^{2}}{2}\right]_{0}^{z^{*}}=\frac{2 m \cdot z^{*}}{\left(T_{o}\right)^{2}} z^{*}-\frac{m}{\left(T_{o}\right)^{2}} \cdot \frac{\left(z^{*}\right)^{2}}{2}=\frac{3}{2} \cdot \frac{m\left(z^{*}\right)^{2}}{\left(T_{o}\right)^{2}}
\end{gathered}
$$

After substituting the formula (3.8) in the place of integrand (3.4), one obtains now

$$
\begin{gathered}
L_{R}=\int_{0}^{z^{*}}\left[\frac{2 m \cdot z^{*}}{\left(T_{o}\right)^{2}}+m g-\frac{m}{\left(T_{o}\right)^{2}} z\right] d z=\frac{2 m \cdot z^{*}}{\left(T_{o}\right)^{2}} \int_{0}^{z^{*}} d z+m g \int_{0}^{z^{*}} d z-\frac{m}{\left(T_{o}\right)^{2}} \int_{0}^{z^{*}} z d z= \\
=\frac{2 m \cdot z^{*}}{\left(T_{o}\right)^{2}}[z]_{0}^{z^{*}}+m g[z]_{o}^{z^{*}}-\frac{m}{\left(T_{o}\right)^{2}}\left[\frac{z^{2}}{2}\right]_{0}^{z^{*}}=\frac{2 m\left(z^{*}\right)^{2}}{\left(T_{o}\right)^{2}}+m g \cdot z^{*}-\frac{m}{\left(T_{o}\right)^{2}} \cdot \frac{\left(z^{*}\right)^{2}}{2}= \\
=\frac{3}{2} \cdot \frac{m\left(z^{*}\right)^{2}}{\left(T_{o}\right)^{2}}+m g \cdot z^{*}
\end{gathered}
$$

By regarding the values of magnitudes $m, g, T_{o}, z^{*}\left(m=2.82 \mathrm{~kg} ; g=9.81 \mathrm{~m} \cdot \mathrm{s}^{-2}\right.$; $\left.z^{*}=7.835 \cdot 10^{-3} \mathrm{~m} ; T_{o}=69.823 \mathrm{~s}\right)$ in the formulae (2.19 [3]), (3.7) and (3.8), one obtains

$$
\begin{gathered}
Q=m g=2.82 \cdot 9.81=27.66 \mathrm{~N} \\
B_{z}=\frac{2 m \cdot z^{*}}{\left(T_{o}\right)^{2}}-\frac{m}{\left(T_{o}\right)^{2}} z=\frac{2 \cdot 2.82 \cdot 7.835 \cdot 10^{-3}}{(69.823)^{2}}-\frac{2.82}{(69.823)^{2}}= \\
=9.05 \cdot 10^{-6}-5.78 \cdot 10^{-4} z
\end{gathered}
$$

with the value for $z=0$, the inertia force $B_{z}=9.05 \cdot 10^{-6} \mathrm{~N}$, and for $z=z^{*}=7.835 \cdot 10^{-3} \mathrm{~m}$ that force equals $4.53 \cdot 10^{-6} \mathrm{~N}$.

The repel force $R_{z}$, calculated acc. to the formula (3.8), equals 


$$
\begin{gathered}
R_{z}=\frac{2 m \cdot z^{*}}{\left(T_{o}\right)^{2}}+m g-\frac{m}{\left(T_{o}\right)^{2}} z=\frac{2 \cdot 2.82 \cdot 7.835 \cdot 10^{-3}}{(69.823)^{2}}+2.82 \cdot 9.81-\frac{2.82}{(69.823)^{2}} z= \\
=9.05 \cdot 10^{-6}+27.66-5.78 \cdot 10^{-4} z
\end{gathered}
$$

with the value for $z=0$ the repel force $R_{z}=\left(9.05 \cdot 10^{-6}+27.66\right) \mathrm{N}$, whereas for $z=z^{*}=7.835 \cdot 10^{-3} \mathrm{~m}$ that force equals $\left(27.66+4.53 \cdot 10^{-6}\right) \mathrm{N}$.

Having at disposal the values of magnitudes $m, g, z^{*}, T_{o}$, one may calculate now, according to the formulae (3.3), (3.9), and (3.10), particular works, such as: gravity $L_{Q}$, inertia $L_{B}$, and repel $L_{R}$. Therefore

$$
\begin{gathered}
L_{Q}=Q \cdot z^{*}=m g \cdot z^{*}=2.82 \cdot 9.81 \cdot 7.835 \cdot 10^{-3}= \\
=216.75 \cdot 10^{-3}=216750 \cdot 10^{-6} \mathrm{~J} \\
L_{B}=\frac{3}{2} \cdot \frac{m\left(z^{*}\right)^{2}}{\left(T_{o}\right)^{2}}=\frac{3}{2} \cdot \frac{2.82\left(7.835 \cdot 10^{-3}\right)^{2}}{(69.823)^{2}}=0.053 \cdot 10^{-6} \mathrm{~J} \\
L_{R}=\frac{3}{2} \cdot \frac{m\left(z^{*}\right)^{2}}{\left(T_{o}\right)^{2}}+m g \cdot z^{*}=\frac{3}{2} \cdot \frac{2.82\left(7.835 \cdot 10^{-3}\right)^{2}}{(69.823)^{2}}+2.82 \cdot 9.81 \cdot 7.835 \cdot 10^{-3}= \\
=0.053 \cdot 10^{-6}+216750 \cdot 10^{-6}=216750.053 \cdot 10^{-6} \mathrm{~J}
\end{gathered}
$$

The work unit is joule $(\mathrm{J})$, that results from operation on the units

$$
\begin{gathered}
{\left[L_{Q}\right]_{S I}=\mathrm{kg} \cdot \frac{\mathrm{m}}{\mathrm{s}^{2}} \cdot \mathrm{m}=\frac{\mathrm{kg} \cdot \mathrm{m}}{\mathrm{s}^{2}} \cdot \mathrm{m}=N \cdot \mathrm{m}=J} \\
{\left[L_{B}\right]_{S I}=\frac{\mathrm{kg} \cdot \mathrm{m}^{2}}{\mathrm{~s}^{2}}=\frac{\mathrm{kg} \cdot \mathrm{m}}{\mathrm{s}^{2}} \cdot \mathrm{m}=N \cdot \mathrm{m}=J}
\end{gathered}
$$

and the equality of units of particular works

$$
\left[L_{R}\right]_{S I}=\left[L_{Q}\right\rfloor_{S I}+\left[L_{B}\right]_{S I}
$$

In Fig. 1, the geometric image of inertia work $L_{B}$ and dependence of inertia force $B_{z}$ on the displacement $z$ of tool, are presented.

Fig. 2 presents this kind of image of the gravity work $L_{Q}$ and dependence gravity force $Q$ on the displacement $z$ of tool.

In Fig. 3, there is the geometric image of the repel work $L_{R}$ and the dependence of repel force $R_{z}$ on the displacement of tool. Particular works are presented by the dashed areas under the plots of corresponding to them the dependences of forces on the higher described the independent variable $z$. 


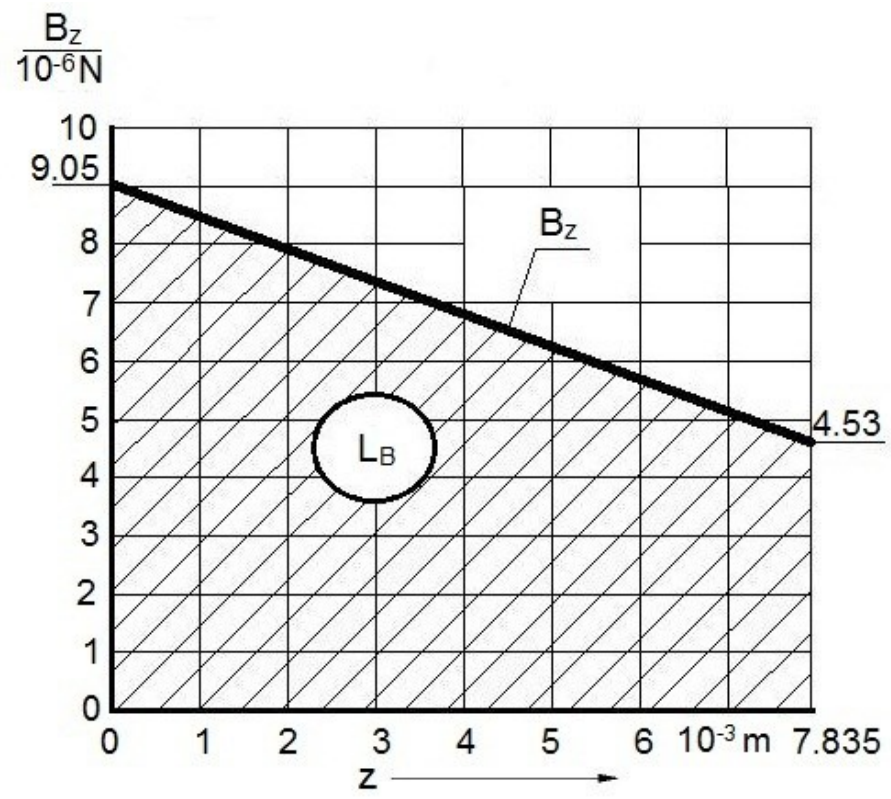

Fig. 1. Geometric image of inertia work $L_{B}$ and the dependence of inertia force $B_{z}$ on the displacement $z$ of tool.

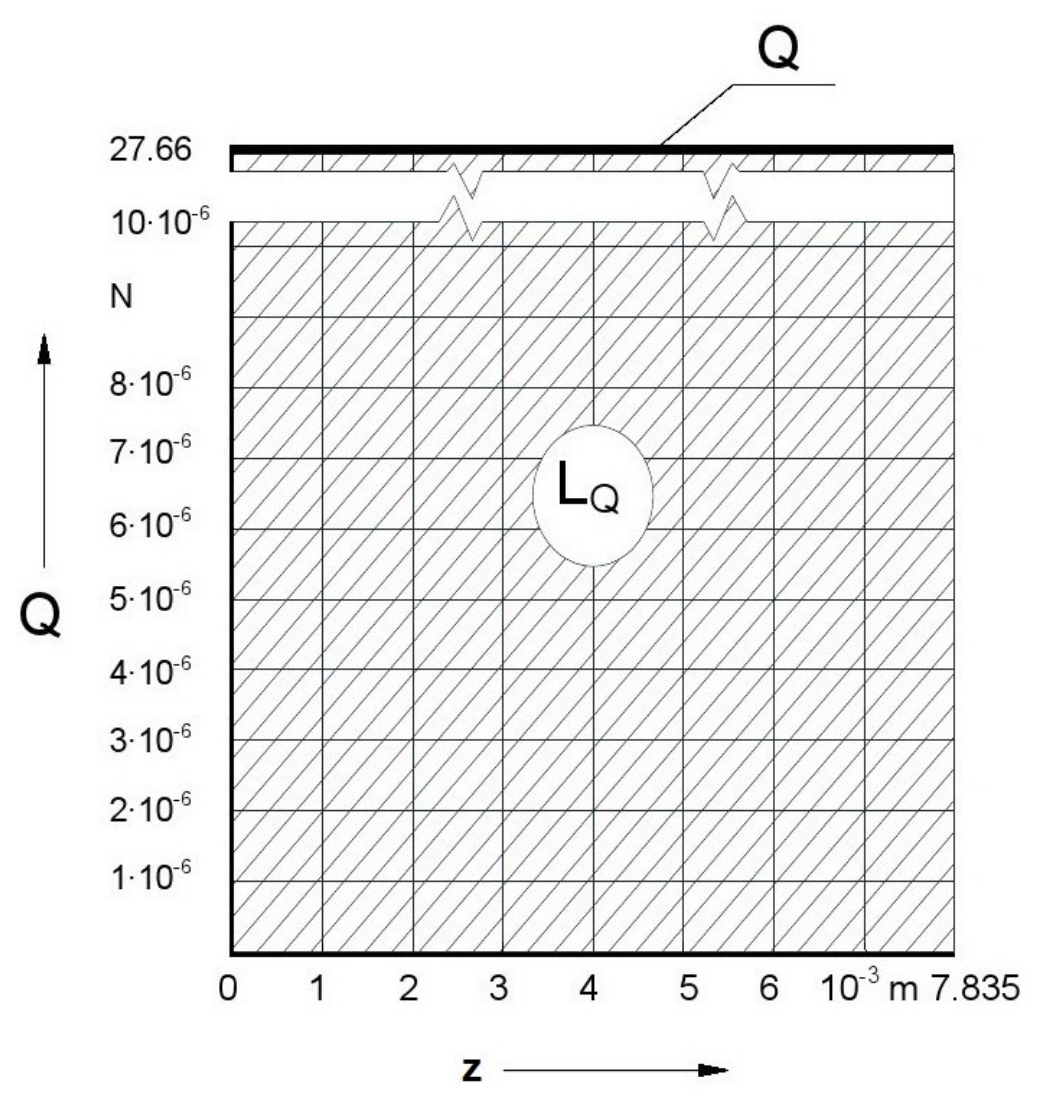

Fig. 2. Geometric image of gravity work $L_{Q}$ and the dependence of gravity force $Q$ on the displacement $z$ of tool. 


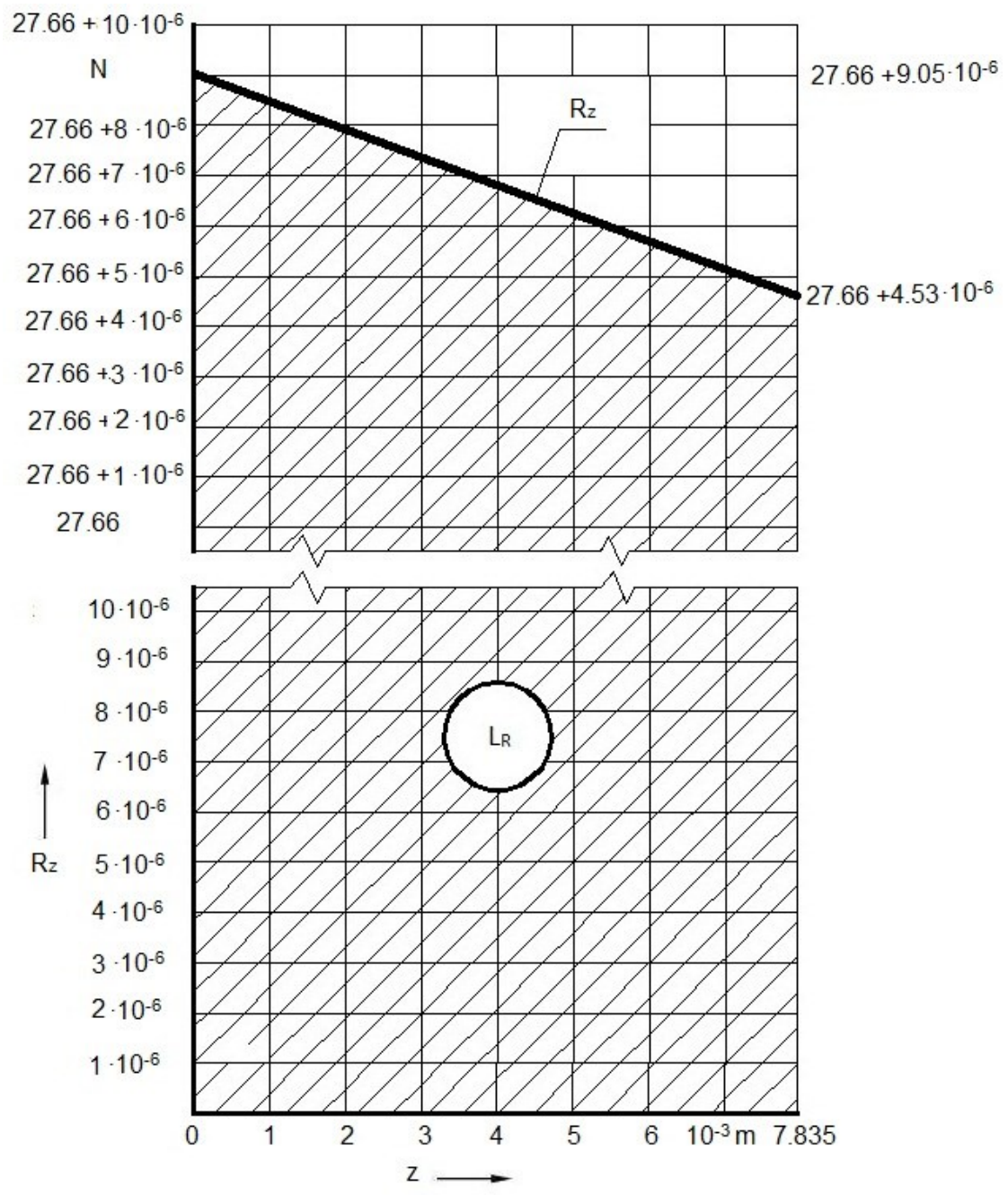

Fig. 3. Geometric image of repel work $L_{R}$ and the dependence of repel force $R_{z}$ on the displacement $z$ of tool.

\section{ENERGY OF THE SOLID/TOOL FIXED FLEXIBLY}

All magnitudes considered earlier [1-3], both kinetic and dynamic ones, described the tool behaviour in the machining zone. The tool was moving in vertical direction between the neighbouring potential fields: stable static potential field SSPF and instantaneous unstable static potential field $(A S P F)^{*}$. On these fields the cutting tool possessed determined energetic states. On the bottom field, that is $S S P F$, it was under the stable energetic state, whereas on the upper field $(A S P F)^{*}$ there was the instantaneous unstable energetic state noted [4-9].

That is a generally clarified matter of stored energy of the solid/tool fixed flexibly. It is clearly evident that the energy cannot characterize a tool placed in the space-time. Therefore the work, as one of many dynamic magnitudes, is not an energy nor its measure. Thus the identification of energy with work is groundless and erroneous.

It is time now to clarify the matter. However, first the existent knowledge on mechanical energy, which is the energy of a solid, is to be given. It is worth noting that it is 
impossible rather to present all aspects of the problem in this paper. Here some literature references, concerning energetic aspects of the reality, will be delivered.

At the beginning, let us start with the definition of energy, as the notion of this magnitude is fundamental and primary for further considerations. Of course, there is a definition of energy in the literature but it is detached from the reality, or no clearly précised connection is noticed. Some even say there is no definition of the notion. The question is then, why this notion is used if it is essenceless? Is it really contentless? And, maybe it is too difficult?

The author of the work [10] attempts to explain it; he does it with a surprising sincerity „(...) It seems that is much easier to understand what is the entropy than that what is energy. It is difficult to provide a strict definition of energy. One may vaguely account that it is ability of a body to perform work, or some property of bent/crooked space-time, or even the crook itself. But to be sincere, none of the definitions is sufficiently convincing. Instead, understanding of the entropy does not present any difficulties (...)”.

The scientific actions, aiming at formulation of the adequate definition of energy, have halted in the point, where the energy is identified with work. It is worth providing at least some examples of elaborations which confirm this thesis. It is stated in the work [11] that the mechanical energy in the state I against state II is called the work provided by a system under transition from state I to state II. Literature [12] treats the energy as a scalar physical magnitude, expressed in the units of work, determining the ability of a body or bodies system to perform a work under transition from one state to the other. Definition of energy, given in work [13], explains that the energy is the magnitude being the measure of ability of a material system to perform the mechanical work.

Literature [10] provides information that the notion of energy, as a scientific term, on the ground of science was introduced for the first time in 1807, when Thomas Young (17731829), professor of natural philosophy at the Royal Institution of Great Britain, defined it as a product of mass (or weight) of a body and its velocity under the second power. In 1820 - as provides that literature - that formula was corrected by substituting the unit factor by the factor equal 0.5. As it appears, that correction was introduced only for the purpose to equalize the kinetic energy with work. Thus until today the energy is identified with work none the less there is a big difference between these magnitudes.

Naturally, there were attempts undertaken to change that state-of-art. Some exemplary elaborations [14-17] prove of that. In those works, the existent state of knowledge on the energy issue has been evaluated critically, indicating that the energy is the mental notional magnitude. Hence, it cannot be measured. Furthermore then it results that it does not have a physical nature or character.

The word ,ability” has a primary meaning in the definition of energy, so it must be put on the first place, in accordance with the rule of system [18]. In these circumstances one cannot overlook the definition of term: «potential efficiency, possibility of doing something, suitability for something». That definition has been excerpted from the vocabulary [13]. According to that vocabulary, the word ,potential" means: «sticking to something, able to occur, appear in determined conditions, by a proper action; presumable, assumable, possible to occur/appear»».

In the context of these explanations, one cannot identify the energy with work. It is a mental magnitude and this is why a determined measure should be assigned to it. Not earlier than this measure will be the physical magnitude. The potential is this measure. 
Now the adequate extended definition of energy may be given because not all factors of the reality have been taken into account. It is about the mechanical energy, as such refers to the described here reality.

The mechanical energy, or the energy of solid, is not only the ability to perform the mechanical work. That energy is connected with the need over performing work on a determined body. Such a kind of energy may also indicate on the need to perform work over the body ties with other body. Thus the mechanical energy is the ability to perform work by a body, the need to perform work over body or the body ties with other body. There are two kinds of mechanical energy: active, meaning the ability to perform work by a body; and passive, informing of the need to perform work over or the body ties with other body.

Now that general definition of mechanical energy should be referred to the considered technological reality. The active energy is concerned with the machined workpiece which performs work over the tool. The passive energy refers to the tool and its gravitational ties with Earth. This is about the following energies: repel, inertia, and gravitational.

It is time now to determine measures of these particular energies, i.e. potentials. There will be considered the potentials of energy on the stable static potential field $\operatorname{SSPF}$ (Fig. 4). All these energies are the static mechanical energies, as they refer to the static field. Potential is defined as the product of intensity of a potential field by the distance between the neighbouring potential fields (here it concerns the height of space-time, i.e. $z^{*}$ ). Intensity of the potential field is reflected simply by a determined force.

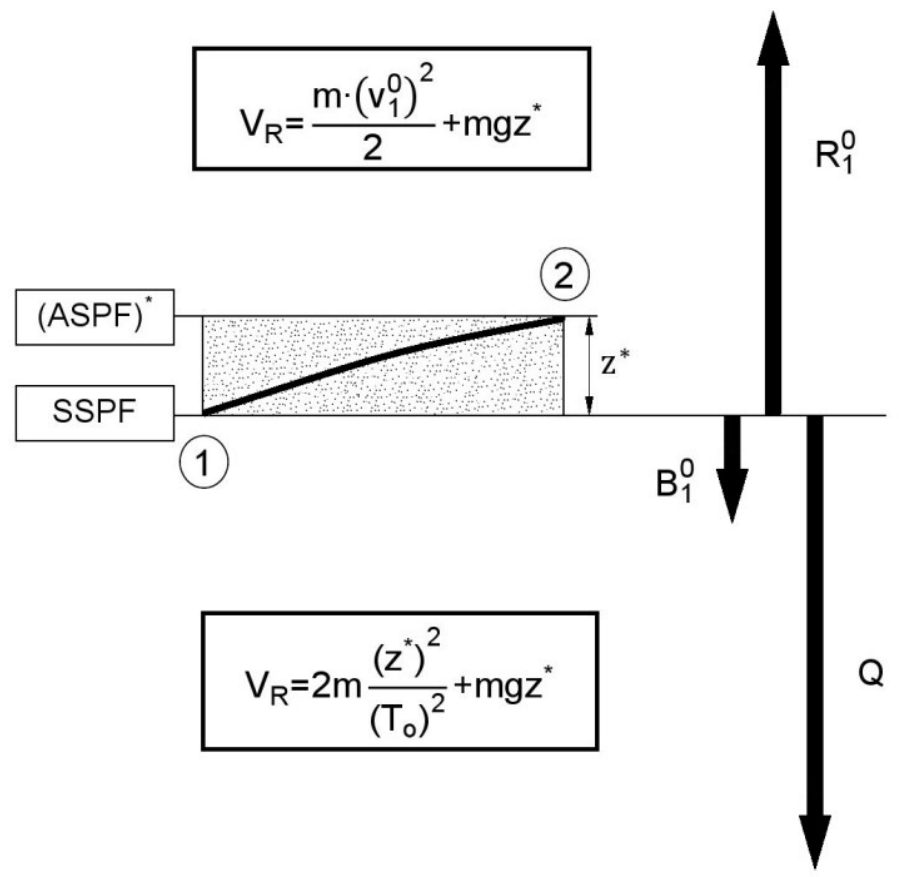

Fig. 4. Machining space-time (dotted area) and the system of initial forces on the stable static potential field.

One may differentiate here the repel potential

$$
V_{R}=R_{1}^{0} \cdot z^{*}
$$


inertia potential

$$
V_{B}=B_{1}^{0} \cdot z^{*}
$$

and the gravity potential

$$
V_{Q}=Q \cdot z^{*}
$$

where the symbols $R_{1}^{0}$ and $B_{1}^{0}$ denote the initial repel force (in point 1) and the initial force of inertia at the same point, respectively. Therefore

The repel potential is naturally equal to the sum of potentials of: inertia, and gravity.

$$
V_{R}=V_{B}+V_{Q}
$$

That means at the same time that the active potential is the sum of passive potentials.

One may develop now the formulae on determined potentials. It results from the formula (2.5 [3]) that

$$
B_{1}^{0}=m \frac{2 z^{*}}{\left(T_{o}\right)^{2}}=\frac{m v_{1}^{0}}{T_{o}}
$$

Regarding then (3.24) in the formula (3.21), one obtains

$$
\begin{gathered}
V_{B}=B_{1}^{0} \cdot z^{*}=m \frac{2 z^{*}}{\left(T_{o}\right)^{2}} \cdot z^{*}=m \frac{2\left(z^{*}\right)^{2}}{\left(T_{o}\right)^{2}}= \\
=m \frac{2 z^{*}}{T_{o}} \cdot \frac{z^{*}}{T_{o}}=m v_{1}^{0} \frac{v_{1}^{0}}{2}=\frac{m\left(v_{1}^{0}\right)^{2}}{2}
\end{gathered}
$$

Comparing (3.25) with (3.9), which are the formulae on the inertia work $L_{B}$ and inertia potential $V_{B}$, one states that

$$
\left.V_{B}\right\rangle L_{B}
$$

as

$$
V_{B}=2 \frac{m\left(z^{*}\right)^{2}}{\left(T_{o}\right)^{2}}
$$

and

$$
L_{B}=\frac{3}{2} \cdot \frac{m\left(z^{*}\right)^{2}}{\left(T_{o}\right)^{2}}
$$

Dividing $V_{B}$ by $L_{B}$, one obtains the following dependence: 


$$
V_{B}=\frac{4}{3} L_{B}
$$

Therefore the inertia potential is directly proportional to the inertia work, and the coefficient of proportionality has the value higher than one.

It results from the formulae (3.3) and (3.22) that the gravity potential $V_{Q}$ is equal to the total gravity work of tool, that is the work on the path corresponding with the distance between the neighbouring potential fields:

$$
V_{Q}=L_{Q}=m g \cdot z^{*}
$$

Thus, after substituting the formulae (3.25) and (3.30) to (3.23), one obtains

$$
V_{R}=2 m \frac{\left(z^{*}\right)^{2}}{\left(T_{o}\right)^{2}}+m g \cdot z^{*}
$$

or

$$
V_{R}=\frac{m\left(v_{1}^{0}\right)^{2}}{2}+m g \cdot z^{*}
$$

That is the form being the law of conservation of potentials, i.e. the measure of energy. That means the repel potential is equal the sum of inertia potential and the gravity potential.

\section{CONCLUSION}

In the framework of extended analysis, the notion of energy has been explained, with a special attention to the mechanical energy. It was proved that the energy is not a physical magnitude, but it is rather a mental magnitude, to which a determined measure should be assigned. A determined potential, with the name resulting from the kind of force on the potential field, fulfils the measure role of mechanical energy.

One may state the fact of filling up a gap of existing cognitive nature in the context of stored energy of the tool fixed flexibly. It was filled up with the notion of energy, a fundamental notion in the determined reality in view of understanding it properly. That is a pity, even the latest literature [19-20], devoted to the mechanics of solids, have not taken into consideration that classical method of investigation, acc. to which each problem should be begun from the so called status questionis, i.e. the explanation of notions and their definitions.

\section{References}

[1] Zdzisław Pluta, Tadeusz Hryniewicz, International Journal of Advanced Manufacturing Technology 62(5) (2012) 529-542; DOI: $10.1007 / \mathrm{s} 00170-011-3813-5$

[2] Zdzisław Pluta, Tadeusz Hryniewicz, International Letters of Chemistry, Physics and Astronomy 10(1) (2013) 35-47. 
[3] Zdzisław Pluta, Tadeusz Hryniewicz, International Letters of Chemistry, Physics and Astronomy 10(1) (2013) 110-118.

[4] Zdzisław Pluta, Tadeusz Hryniewicz, International Letters of Chemistry, Physics and Astronomy 4 (2012) 8-16.

[5] Zdzisław Pluta, Tadeusz Hryniewicz, International Letters of Chemistry, Physics and Astronomy 5 (2012) 35-45.

[6] Zdzisław Pluta, Tadeusz Hryniewicz, International Letters of Chemistry, Physics and Astronomy 3 (2013) 67-84.

[7] Zdzisław Pluta, Tadeusz Hryniewicz, International Letters of Chemistry, Physics and Astronomy 7(2) (2013) 85-101.

[8] Zdzisław Pluta, Tadeusz Hryniewicz, Journal of Quantum Information Science (JQIS) 1(3) (2011) 127-134, DOI: $10.4236 /$ jqis.2011.13018.

[9] Zdzisław Pluta, Tadeusz Hryniewicz, Journal of Quantum Information Science (JQIS) 1(3) (2011) 149-160

DOI: $10.4236 /$ jqis.2011.13021.

[10] P. Atkins, Galileo's finger (in Polish), Editorial House REBIS. Poznań, 2006, $1^{\text {st }}$ edition.

[11] M. Szymczak, (ed.), Polish vocabulary, Vol. 1, A - K, Warszawa, 1978.

[12] B. Petrozolin-Skowrońska, (ed.), Popular Encyclopaedia PWN (in Polish), Vol. 2, Świat Książki, Warszawa, 1987.

[13] M. Jeżewski, Physics (in Polish), PWN, Warszawa, 1966, 9th edition.

[14] Tadeusz Hryniewicz, Zdzisław Pluta, Understanding the Teaching Process or the Lost Essence of Energy, Proc. of the $8^{\text {th }}$ World Conference on Continuing Engineering Education, Theme A: Knowledge, Skills and Competency, May 12-16, 2001, Toronto, Ontario, Canada, 2001, pp. 25-31.

[15] Zdzisław Pluta, Forum Akademickie 3 (1999) 56-58, 6th year, (Return to the sources).

[16] Zdzisław Pluta, LAB (Laboratoria, Aparatura, Badania) 4 (2005) 43-46, 10th year.

[17] Zdzisław Pluta, Energetyka 7 (2005) 496-501, 65th year.

[18] M. Mazur, Technical terminology (in Polish), WNT, Warszawa, 1961.

[19] J. R. Taylor, Classical mechanics (in Polish), PWN, Warszawa, 2006, 1st edition.

[20] L.D. Landau, J. M. Lifszyc, Mechanics (in Polish). PWN, Warszawa, 2006, 4th edition (transl. from Russian). 